\title{
A PROJEÇÃO ASIÁTICA DA INDÚSTRIA TÊXTIL E VESTUARISTA CATARINENSE NOS ANOS 2000: ESTUDO SOBRE TRÊS EXPERIÊNCIAS NO VALE DO ITAJAí
}

\author{
Vanessa Jurgenfeld' \\ Hoyêdo Nunes Lins²
}

\section{Resumo}

Nos anos 2000, fabricantes têxteis e vestuaristas de Santa Catarina passaram a encomendar a produção de artigos prontos e semiacabados na Ásia, principalmente na China, objetivando ampliar e diversificar a sua oferta no mercado brasileiro e no exterior. O câmbio foi determinante nesse movimento, que implica governança com coordenação e imposição de parâmetros produtivos pelos compradores junto aos fornecedores. Este artigo analisa essa estratégia baseado em entrevistas em três empresas do Vale do Itajaí (SC) - Hering, Teka e Buettner - e em instituições locais. Mostra-se que, procurando a Ásia, as empresas buscam presença em ambiente que representa o referencial mundial de preços nessas atividades, por conta da mão de obra mais barata e do alto nível de qualidade. Mas a produção asiática é complementar à realizada pelas empresas, sem desativação de linhas de produtos locais. Todavia, houve ajustes no planejamento da produção, sobretudo quanto à concepção e ao lançamento das coleções.

Palavras chaves: Cadeias mercantis globais; indústria têxtil e vestuarista; Vale do Itajaí; Ásia.

Classificação JEL: L24, L27

Bacharel em Ciências Econômicas pela Universidade Federal de Santa Catarina e Mestranda em Desenvolvimento Regional na Universidade Estadual de Campinas. E-mail: vfollmann@hotmail.com

2 Professor do Departamento de Ciências Econômicas e do Programa de Pós-Graduação em Economia da Universidade Federal de Santa Catarina. E-mail: hnlins@cse.ufsc.br 


\section{INTRODUÇÃO}

Comprar ou mandar fazer em outro país um produto ou serviço, uma prática observada em diferentes setores, ganhou força como tendência após os anos 1970, com rompimento da regulação sobre o fluxo de capital estabelecido por Bretton Woods, estimulando transferências de atividades industriais dos países mais desenvolvidos para outras regiões, menos privilegiadas. Uma verdadeira interdependência entre processos incidentes em países distintamente posicionados na divisão internacional do trabalho, com grandes teias de vínculos contendo fluxos diversos, ganhou corpo aceleradamente e avançou desde então. Uma expressão que capta aspectos centrais dessa arquitetura é "cadeia mercantil global", em cujo debate costuma-se salientar as relações de poder que perpassam esses vínculos. Por exemplo, agentes operando em alguns países protagonizam coordenação e controle ao impor condições de produção junto a agentes em outros países. Os primeiros geralmente representam elos em países mais ricos (na América do Norte e Europa Ocidental, por exemplo) e os segundos, em vários lugares (países, regiões) de América Latina, Ásia e África.

A indústria têxtil e vestuarista de Santa Catarina, uma das mais importantes desse estado, participa do que se pode chamar de "cadeia têxtil global", expressão que evoca a trama de relações internacionais enfeixadas na produção e distribuição de artigos têxteis e de vestuário. Atividades principalmente localizadas no Vale do Itajaí, sobretudo em Blumenau, inserem-se nessa cadeia, como ilustrado pelas vendas para clientes estrangeiros que comercializam esses produtos nos seus próprios mercados.

Na década de 2000, algumas dessas empresas passaram a incorporar ao seu leque de oferta produtos originários da Ásia, prontos ou semiacabados, para venda no mercado nacional e no exterior. O início desse processo prefigurou movimento que alcançou considerável dimensão no Brasil (Fornetti, 2010). Essa "nova" internacionalização das atividades têxteis e vestuaristas do Vale do Itajaí é o objeto deste artigo, que se baseia em pesquisa de campo junto a três importantes empresas da região: Hering, Buettner e Teka. O estudo recobre-lhes as atividades de importação de produtos acabados e semiacabados no período entre 2003 e 2008, objetivando analisar as ações executadas, com indicação das circunstâncias e motivações, e detectar as 
implicações. O assunto é relevante especialmente porque o Vale do Itajaí abriga um dos mais importantes aglomerados têxteis e vestuaristas do Brasil, com quatro mil empresas, entre pequenas, médias e grandes, que possuem 131 mil empregados (SINTEX, 2009).

Na próxima seção se "demarca" o terreno do debate sobre cadeias mercantis globais, para situar o estudo. Depois, olha-se para o comércio externo envolvendo as atividades têxteis e vestuaristas de Santa Catarina na década de 2000. A parte seguinte "apresenta" as três empresas estudadas, a partir do que, em outra seção, descreve-se e analisa-se a "nova" modalidade de interação de grandes empresas do Vale do Itajaí com a Ásia. Por último, antes das considerações finais, apresenta-se uma visão de conjunto sobre os determinantes e implicações das estratégias de internacionalização estudadas.

\section{REFERENCIAL ANALÍTICO: A PROBLEMÁTICA DAS CA- DEIAS MERCANTIS GLOBAIS}

Cadeia mercantil global é noção básica na abordagem da trajetória do capitalismo na perspectiva dos sistemas-mundo, elaborada sob a liderança intelectual de Wallerstein (2000), inspirada em Braudel (1996) e incorporada por Arrighi (1997) em análises sobre o desenvolvimento econômico no século XX. Nessa utilização, tais cadeias aparecem como redes de vínculos envolvendo a produção e circulação das mercadorias necessárias à reprodução de uma economia-mundo, ou de "um fragmento do universo, um pedaço do planeta economicamente autônomo, capaz (...) de bastar a si próprio e ao qual suas ligações e trocas internas conferem certa unidade orgânica" (Braudel 1996, p. 2).

Mas as cadeias mercantis globais não têm presença analítica limitada aos estudos sobre o capitalismo histórico. Destacam-se igualmente em pesquisas sobre a contemporânea globalização da economia, traduzida em profunda internacionalização dos processos produtivos e de distribuição. Sua centralidade nessas análises reflete a constatação de que, embora países industrialmente inexpressivos em termos históricos tenham galgado posições na geografia da produção industrial, as diferenças de desenvolvimento entre estados nacionais e regiões subsistem, impondo indagações sobre a natureza da sua participação nos vínculos produtivos e comerciais de al- 
cance global. Postula-se que, como o enfoque das cadeias salienta o "modo como firmas, países e regiões participam do processo global de produção e troca" (Kaplinsky, 2000, p. 6), seu emprego permite, "acima e abaixo do estado-nação, (...) melhor analisar a estrutura e as mudanças na economia mundial" (Gereffi, Korzeniewicz \& Korzeniewicz, 1994, p.2).

Ilustração importante nesse campo de estudo é a desintegração vertical das atividades de empresas transnacionais, envolvendo países e regiões de menor nível de desenvolvimento nas redes que caracterizam essas estruturas econômicas, abrangendo os problemas de coordenação em grande escala e os reflexos territorialmente localizados. A proliferação de propostas analíticas para essa problemática parece um movimento quase natural (cf. p. ex. Henderson et al, 2002).

Os trabalhos de Gereffi $(1994,1995)$ têm grande destaque na abordagem dessa temática. Estudos desse autor na década de 1990 apontam duas formas básicas de cadeia global, considerando o exercício da governança em escala de rede. De um lado, as buyer driven chains (cadeias comandadas por compradores), lideradas por grandes atacadistas, varejistas ou redes de lojas que possuem marcas e dominam o acesso ao mercado. Setores de bens de consumo (vestuário, brinquedos, eletrônicos populares) são típicos dessas cadeias, cujo desdobramento internacional acelerou-se entre os anos 1950 e 1970 e marcou o crescimento industrial de diversos países que avançaram em exportações de manufaturados. De outro lado, as producer driven chains (cadeias comandadas por produtores), em que o poder e o comando pertencem a empresas multinacionais que fabricam mercadorias como carros e computadores e localizam suas atividades - envolvendo subsidiárias, fornecedores, subcontratados e esquemas de distribuição - em diferentes países e regiões.

Nas buyer driven chains, os determinantes da produção - realizada em redes dispersas mundialmente e fragmentadas em termos organizacionais, com fabricantes geralmente localizados onde os custos de mão de obra são mais baixos - são estabelecidos pelos grandes compradores, que os impõem às empresas participantes. Nas producer driven chains, cabe às empresas principais determinar e impor os aspectos técnicos e tecnológicos da produção, definir o design e protagonizar o marketing, controlando e coordenando atividades em distintos países. 
Mais recentemente surgiu uma tipologia detalhada das formas de governança em cadeias (Gereffi, Humphrey \& Sturgeon, 2005). Entre os casos opostos de relações interfirmas baseadas no mercado e com pouca assimetria de poder - representando baixos custos de mudança de parceiros, quando isso acontece - e de integração vertical com alta assimetria de poder - apresentando coordenação que envolve hierarquias, o controle fluindo em direção às empresas subsidiárias ou afiliadas - , identificam-se três tipos de relações em redes. Nas modular value chains (cadeias de valor modulares) a produção segue as especificações dos clientes, mas os fornecedores têm capacidade em tecnologia de processo e para gastos objetivando enriquecer as relações com os primeiros. Como compradores e fornecedores interagem com numerosos parceiros, não há praticamente restrições à substituição de vínculos, sendo baixas, portanto, as assimetrias de poder. Nas relational value chains (cadeias de valor relacionais), as interações entre fornecedores e clientes são complexas, de mútua dependência e presença de ativos específicos. Confiança e reputação são elementos centrais na gestão dos vínculos, e as relações de poder mostram equilíbrio entre os participantes, pois fornecedores e clientes possuem competências estratégicas: a coordenação, embora intensa e explícita, ocorre por diálogo entre agentes quase iguais. As captive value chains (cadeias de valor cativas) apresentam grande dependência de pequenos fornecedores perante grandes compradores, com forte monitoramento e controle exercido pelas firmas líderes, cujo controle é direto, com explícita coordenação, sendo o exercício de poder muito assimétrico. Os custos de substituição de clientes são altos.

A indústria mundial de artigos de vestuário, há décadas organizada em redes globais, exibe progressão do perfil captive value chain para o relational value chain na sua base de fornecimento, instalada principalmente no sudeste asiático. Da montagem de artigos finais, com insumos importados, para o mercado global, avançou-se no adensamento dos vínculos domésticos e na exportação de produtos com maior valor agregado. O notável desempenho de países como China e Indonésia, de mão de obra muito barata comparativamente, confunde-se com a habilidade de seus fabricantes nesse processo: a "crescente capacidade dos fornecedores tem sido a principal força por trás da mudança das cadeias de valor cativas para 
as cadeias relacionais na indústria de vestuário (...)" (Gereffi, Humphrey \& Sturgeon, 2005, p. 92).

\section{COMÉRCIO EXTERNO DA INDÚSTRIA TÊXTIL E VESTUA- RISTA CATARINENSE NO PERÍODO RECENTE}

Examinar as relações comerciais externas da indústria têxtil e vestuarista catarinense no período recente mostra utilidade para o pretendido neste estudo. Entre 2003 e 2008, chama primeiramente a atenção o crescimento das importações: o valor dobrou a cada ano, produzindo déficit comercial que se aprofundou no final da série (Tabela 1).

Tabela 1 - Santa Catarina: balança comercial têxtil e vestuarista entre 2003 e 2008 (mil US\$ FOB)

\begin{tabular}{|c|c|c|c|}
\hline Ano & Exportação & Importação & Saldo \\
\hline 2003 & 307.276 & 50.464 & 256.812 \\
\hline 2004 & 354.136 & 96.190 & 257.946 \\
\hline 2005 & 351.979 & 138.866 & 213.113 \\
\hline 2006 & 322.096 & 316.478 & 5.617 \\
\hline 2007 & 313.643 & 572.611 & -258.967 \\
\hline 2008 & 262.736 & 867.439 & -604.702 \\
\hline
\end{tabular}

Fonte: SINTEX, com base em dados do MDIC

As maiores importações provêm de China, Índia e Indonésia. Somados, os valores oscilam de quase $37 \%$ a quase $70 \%$ do total catarinense entre 2003 e 2008 (Tabela 2). Mas a trajetória é de forte ascensão, com duplicação do seu peso na pauta catarinense. China e Índia tornaram-se as principais origens dessas compras, mas, até 2006, era a Indonésia a mais importante fonte asiática. Pelas informações de Buettner, Hering e Teka, não há praticamente diferença nos tipos de importações oriundas desses países, somente variando o preço. 
Tabela 2 - Santa Catarina: principais origens das importações têxteis e vestuaristas entre 2003 e 2008 (mil US\$ FOB)

\begin{tabular}{|l|c|c|c|c|c|c|}
\hline \multicolumn{1}{|c|}{ Países } & 2003 & 2004 & 2005 & 2006 & 2007 & 2008 \\
\hline China & 2.490 & 4.587 & 14.890 & 68.178 & 152.271 & 243.244 \\
\hline Índia & 2.036 & 6.992 & 13.961 & 33.305 & 69.580 & 223.223 \\
\hline Indonésia & 14.114 & 25.477 & 33.255 & 79.593 & 141.818 & 139.413 \\
\hline Sub-total (A) & 18.640 & 37.056 & 62.107 & 181.078 & 363.669 & 605.881 \\
\hline Total importado (B) & 50.464 & 96.190 & 138.866 & 316.478 & 572.611 & 867.439 \\
\hline A:B * 100 & 36,9 & 38,5 & 44,7 & 57,2 & 63,5 & 69,8 \\
\hline
\end{tabular}

Fonte: ABIT, com base em dados do MDIC

É grande a participação de fios, filamentos e confecções nessas importações (Tabela 3). Trata-se, portanto, não só de insumos, mas também de produtos semielaborados e acabados. O crescimento dessas compras foi significativo a partir de 2006, observando-se expansão até 2008, quando o nível atingido foi histórico. Além daqueles itens, também cresceu a importação de fibras têxteis, embora menos intensamente. O mesmo ocorreu com tecidos e com "outras manufaturas", que englobam pastas, feltros e os chamados não tecidos em geral.

Tabela 3 - Santa Catarina: itens têxteis importados entre 2003 e 2008 (US\$ mil FOB)

\begin{tabular}{|l|c|c|c|c|c|c|}
\hline Itens importados & 2003 & 2004 & 2005 & 2006 & 2007 & 2008 \\
\hline Fibras Têxteis & 10.868 & 17.421 & 11.202 & 20.575 & 29.478 & 32.659 \\
\hline Fios & 6.586 & 24.233 & 46.898 & 110.485 & 260.227 & 356.533 \\
\hline Filamentos & 19.762 & 34.699 & 38.599 & 95.293 & 143.145 & 209.430 \\
\hline Tecidos & 4.846 & 5.768 & 10.752 & 19.327 & 33.630 & 80.244 \\
\hline Linhas de costura & 33 & 109 & 107 & 440 & 422 & 265 \\
\hline Confecções & 2.756 & 5.641 & 15.264 & 45.657 & 65.302 & 131.836 \\
\hline Outras manufaturas & 5.584 & 8.319 & 16.043 & 24.702 & 40.415 & 56.473 \\
\hline
\end{tabular}

Fonte: ABIT, com base em dados do MDIC 
Dois itens pertencentes à rubrica "confecção" merecem atenção: vestuário e artigos para cama, mesa e banho, cujo avanço a partir de 2006 foi considerável, o patamar alcançado em 2008 revelando-se muito alto em termos absolutos e também proporcionais (Tabela 4). Em artigos de vestuário, além da Hering (empresa estudada neste trabalho), também a Marisol, de Jaraguá do Sul, tem grande destaque em Santa Catarina. Em produtos para cama, mesa e banho, o estado possui o maior aglomerado no país: ao lado de Buettner e Teka, participantes desta pesquisa, observa-se a forte presença de Karsten, Altenburg, Coteminas (ex-Artex) e Döhler.

Tabela 4 - Santa Catarina: peso das importações dos segmentos de vestuário e de artigos para cama, mesa e banho entre 2003 e 2008 (US\$ mil FOB)

\begin{tabular}{|l|c|c|c|c|c|c|}
\hline Itens importados & 2003 & 2004 & 2005 & 2006 & 2007 & 2008 \\
\hline Artigos de vestuário & 2.130 & 3.689 & 12.378 & 41.473 & 54.097 & 111.499 \\
\hline $\begin{array}{l}\text { Artigos para cama, } \\
\text { mesa e banho }\end{array}$ & 482 & 1.360 & 2.313 & 3.135 & 8.786 & 16.668 \\
\hline Sub-total (A) & 2.612 & 5.049 & 14.691 & 44.608 & 62.883 & 128.167 \\
\hline Total importado (B) & 50.464 & 96.190 & 138.866 & 316.478 & 572.611 & 867.439 \\
\hline A:B*100 & 5,18 & 5,24 & 10,6 & 14 & 10,9 & 14,8 \\
\hline
\end{tabular}

Fonte: ABIT, com base em dados do MDIC

\section{TRÊS IMPORTANTES EMPRESAS DO VALE DO ITAJAII: BUETTNER, HERING E TEKA}

Buettner, Hering e Teka destacam-se nacionalmente nos segmentos em que atuam. A Hering, criada em Blumenau e envolvida principalmente com artigos de vestuário, é a que possui o maior faturamento, além de ser a mais antiga (fundada em 1880) e a única com canal próprio de varejo. A Buettner, criada em 1898 em Brusque, opera nos segmentos de cama, mesa e banho privilegiando consumidores de maior renda. A Teka, também de Blumenau, foi criada em 1926 e produz artigos para cama, mesa e banho mais populares.

A receita líquida é sugestiva das suas trajetórias recentes. Entre 2003 e 2008, a receita da Buettner oscilou entre quase $\mathrm{R} \$ 200$ milhões e pouco mais de R \$ 130 milhões, em declínio; na Teka, passou de cerca de R \$ 210 milhões 
em 2004 para R \$ 305 milhões em 2008; a da Hering superou R \$ 500 milhões em 2008 (Tabela 5). Juntas, essas receitas tangenciaram R \$ 1 bilhão em 2008, ultrapassando o valor importado pelo conjunto da indústria têxtil e vestuarista catarinense naquele ano e representando o triplo das respectivas exportações.

Essas empresas trilharam caminhos distintos nesse período. Hering e Teka aumentaram a produção objetivando maiores ganhos de escala, enquanto a Buettner se concentrou nos consumidores de maior renda. Mas todas protagonizaram reestruturação no começo dos anos 2000, e não por razões fortuitas: seu endividamento em dólar era elevado, e a desvalorização cambial do início de 1999 afetou-lhes enormemente.

Tabela 5 - Buettner, Hering e Teka: receita líquida entre 2003 e 2008 (R\$ mil)

\begin{tabular}{|l|c|c|c|c|c|c|}
\hline Empresa & 2003 & 2004 & 2005 & 2006 & 2007 & 2008 \\
\hline Buettner & 171.836 & 192.087 & 160.338 & 139.446 & 133.255 & 141.524 \\
\hline Hering & 297.723 & 334.190 & 320.295 & 329.976 & 369.243 & 514.461 \\
\hline Teka & 216.631 & 210.926 & 260.703 & 291.044 & 300.401 & 305.484 \\
\hline
\end{tabular}

Fonte: BOVESPA

Teka e Buettner avançaram em profissionalização da gestão, incorporando executivos externos a seus quadros. A segunda logrou administrar suas dívidas renegociando debêntures que não foram pagas no vencimento, e a primeira conseguiu evitar a falência. Suas condições de caixa permaneceram difíceis, todavia. Em 30 de dezembro de 2008, o patrimônio líquido de ambas era negativo em R \$ 59,6 milhões e R \$ 528,8 milhões, respectivamente. Em 2009 a Teka recolocou a presidência nas mãos da família fundadora; na Buettner, o comando continuou o mesmo.

Na Hering, o patrimônio líquido era positivo em 2008. Mas também nessa empresa o início dos anos 2000 trouxe mudanças importantes no modelo de negócio, pois havia dificuldades de caixa. Os esforços privilegiaram o fortalecimento da venda no varejo, multiplicando lojas e diminuindo preços. A busca de novas posições em preço provocou uma forte disputa com cadeias de lojas como Renner e C\&A, para além de embates que só envolviam, praticamente, grifes como Colcci, M. Officer e Forum. Porém não houve abandono do conceito fashion para as roupas, apesar da clara opção pelo varejo. Investiu-se 
agressivamente em franquias e apostou-se no retorno às origens, com preços mais baixos para o que se chamou de "básico que é fashion": a notoriedade inicial da Hering ligava-se à produção de camisetas brancas.

Das três empresas, somente a Hering conseguiu reverter o desempenho mediante reestruturação, voltando a apresentar lucro líquido. Teka e Buettner seguiram em dificuldades e ainda em 2008 apresentavam prejuízo (Tabela 6). Na Hering, 2004 representou a situação mais adversa, e ao final de 2005 seu endividamento era de $\mathrm{R} \$ 201,3$ milhões, pouco menos de cinco vezes a geração de caixa (A velha 2009). Isso contraía as possibilidades de investimento e impedia abertura de lojas em ritmo semelhante ao dos concorrentes. Daí que, antes de avançar no varejo, a empresa se reestruturou entre 2003 e 2006. Um fundo de investimentos injetou-lhe recursos, sustentando estratégia para firmar, além da condição de fabricante, também a de importante varejista. Buettner e Teka atribuíram suas perdas aos efeitos da valorização cambial e às altas taxas de juros, entraves para um consumo doméstico mais dinâmico e à competitividade internacional. Também a maior concorrência no mercado interno, fruto da escalada das importações, foi assinalada.

Foi nesse contexto de adversidades que as três empresas passaram de fato a cogitar novas formas de interação na Ásia. Avançar em competitividade, particularmente quanto aos custos de produção, foi a opção escolhida. As alternativas eram escassas, pois essas empresas amargavam forte concorrência dos asiáticos seja nos mercados externos (países europeus e Estados Unidos, basicamente) ou no mercado nacional, devido à escalada das importações.

Tabela 6 - Buettner, Hering e Teka: lucro líquido entre 2003 e 2008 (R\$ mil)

\begin{tabular}{|c|c|c|c|c|c|c|}
\hline Empresa & 2003 & 2004 & 2005 & 2006 & 2007 & 2008 \\
\hline Buettner & $(1.457)$ & $(2.981)$ & $(6.300)$ & $(21.610)$ & $(14.843)$ & $(12.651)$ \\
\hline Hering & 11.602 & $(17.741)$ & 30.971 & 6.780 & 18.693 & 37.722 \\
\hline Teka & $(150.351)$ & $(103.599)$ & $(79.970)$ & $(99.559)$ & $(89.722)$ & $(177.852)$ \\
\hline
\end{tabular}

Fonte: BOVESPA

Obs: Os parênteses indicam prejuízo

As encomendas dessas empresas na Ásia ganharam força a partir de 2006, três anos depois dos primeiros movimentos perante a crise. O objetivo 
era praticar um bom preço final, quando da colocação do produto no varejo, sem comprimir as margens de lucro. As encomendas se concentraram em itens para cuja produção se utiliza, comparativamente, muita mão de obra: por exemplo, bermudas cargo com oito bolsos e produtos feitos com fios sintéticos, como jaquetas de nylon para coleções de inverno. Na fabricação de produtos para cama, mesa e banho, o fornecimento se concentrou em fios distintos dos convencionais (fios de bambu e percal 300 fios), em viscose e, às vezes, em corantes químicos mais baratos do que os do mercado nacional. Produtos semielaborados como toalhas, com bordado e etiquetagem realizados no Brasil, e produtos prontos como roupões também foram comprados.

Para o presidente do Sindicato das Indústrias de Fiação, Tecelagem e do Vestuário de Blumenau (SINTEX), que no período da pesquisa era membro do Conselho de Administração da Hering, o crescente recurso a fornecedores asiáticos deve-se sobretudo ao fato de que, atualmente, as empresas têxteis e vestuaristas que abdicam de se abastecer na Ásia perdem a "relação com o varejo", prejudicando a sintonia com o novo referencial de preços, amplamente determinado pela produção naqueles países: "à medida que o varejo amplia na Ásia a sua busca de (...) produtos de inverno feitos com tricô e/ou tecidos sintéticos, a tendência é essa. Cria-se um novo referencial de preço no mercado, e o seu produto tem que estar adequado (...). Por isso você também vai fabricar na Ásia."

\section{AS EXPERIÊNCIAS ASIÁTICAS DE BUETTNER, HERING E TEKA}

Quando as entrevistas foram realizadas, basicamente no segundo semestre de 2009, somente a Buettner ainda não havia encomendado produção na Ásia segundo parâmetros produtivos próprios. O motivo é que não encontrara condições favoráveis, embora tivesse expectativas nesse sentido. Já Teka e Hering lançavam mão dessa fonte de abastecimento desde 2006.

\subsection{Teka}

A Teka concentrou-se na encomenda de produtos semielaborados e prontos. O início da produção em fábricas asiáticas ocorreu em 2003, 
destinando-se à subsidiária da empresa na Alemanha, mas essa operação logo ganhou outras dimensões, dirigindo-se ao mercado nacional desde 2006. Em entrevista, o vice-presidente da Teka assim justificou a iniciativa: "A indústria que não tiver um pé na Ásia não vai sobreviver. A revolução têxtil está passando por lá".

Conforme apurado, em 2006 a empresa importou produtos cuja posterior comercialização representou 1\% do seu faturamento. Em 2007 essa porcentagem foi $5 \%$ do faturamento, e em 2008, $6 \%$. Os produtos vêm diretamente para o Brasil e se originam, além da China, também na Índia e no Paquistão. A empresa iniciara compras igualmente no Vietnã, no Camboja e em Bangladesh, fugindo do foi qualificado como pressão altista nos preços chineses.

É sugestivo que a Teka enxergasse na Ásia um "componente" da sua estrutura atual. O motivo é que, em qualquer lugar, deve-se operar considerando o preço médio dos asiáticos, pois o mercado mundial de compradores do setor encontra-se nesse continente, com os departamentos de compras das grandes empresas varejistas lá se situando ou para lá migrando. "Hoje, um cliente americano pede amostras de produtos e me dá o endereço na China para envio", assinalou o vice-presidente.

Como a Teka não tem capacidades produtivas próprias na China ou em qualquer outro país asiático, sua produção nesse continente ocorre só em fábricas de terceiros. Mas se cogitava instalar um escritório local para compras e controle de qualidade. No período da pesquisa, o próprio vice-presidente se ocupava disso, viajava várias vezes por ano. O fato de a Teka possuir quatro fábricas no Brasil - duas em São Paulo e duas em Santa Catarina -, exportando em média $20 \%$ da produção, justificaria o desinteresse em instalar unidades fabris na Ásia.

Apesar da investida na Ásia, a atividade de criação ocorre totalmente no Brasil, com parâmetros próprios. Das fábricas asiáticas vêm produtos semielaborados e prontos que seguem para clientes como varejo multimarcas e grandes varejistas. Produtos de algodão, feitos com percal 300 fios - lençóis da marca Prima Delicatta -, constituem exemplos desses produtos. Também os de 200 fios provêm desse continente. Anteriormente, os de 300 fios não eram produzidos pela Teka Brasil, mas os de 200 fios sim. Um produto como tecido liso, semielaborado, chega à fábrica no Brasil e segue diretamente 
para acabamento, corte e estampa; tornando-se um produto final, segue para a expedição, sendo distribuído aos clientes.

A escolha dos fornecedores asiáticos depende de visitas e avaliações durante cerca de um ano, para assegurar a qualidade desejada e os prazos de entrega esperados. No período da entrevista o vice-presidente costumava viajar com equipe técnica para classificar os fornecedores e detalhar a encomenda, determinando o tipo de trama, os aspectos do produto e o nível de qualidade. Esse procedimento era crucial, pois os clientes da Teka faziam exigências de qualidade sobre a produção asiática. A empresa não mantém contrato de fabricação formal e contínuo com esses fornecedores, apenas "coloca pedidos" com seis meses de antecedência.

Segundo o vice-presidente, os produtos trazidos da Ásia são sofisticados. Itens mais baratos, no seu entendimento, podem ser produzidos nas fábricas que possui no Brasil. Assim, a produção asiática é complementar ao que a Teka fabrica no país. A afirmação seguinte é ilustrativa: "Estou trazendo um [percal] 300 fios porque não tenho condições de produzir aqui. As plantas do Brasil não estão adequadas tecnologicamente para produzir isso".

Antes de se voltar ao mercado brasileiro (em 2006), essas operações asiáticas tinham a Europa como destino: encomendava-se a fabricação de produtos acabados sob o comando da Teka Europa, subsidiária com sede na Alemanha. Essa operação continuava ocorrendo no período da entrevista, com sessenta e dois países atendidos por aquela unidade, mas o processo era agora acompanhado dos fluxos para o Brasil. Assim, a efetiva novidade na internacionalização da Teka nesse período refere-se à produção na Ásia para ampliar e diversificar a oferta da empresa no mercado nacional.

Essa forma de interagir evoca as buyer driven chains referidas anteriormente: a Teka compra produção com base nos seus próprios parâmetros produtivos, acatados pelos fornecedores. Porém, um olhar atento sugere conjugação dos atributos de relational value chains e modular value chains. Como a Teka, os fornecedores asiáticos exibem competências estratégicas, pois abastecem distintos compradores de diferentes países, com domínio da tecnologia de processo e capacidade para investir. A Teka "coordena" a relação na Ásia, determinando o que seus fornecedores produzem e monitorando o processo, mas a assimetria de poder, se existe, parece mínima. 


\subsection{Hering}

Além de fabricante, a Hering se considera uma empresa de varejo, com lojas próprias e franqueadas no Brasil e no exterior. Primeira exportadora brasileira de artigos de vestuário, ainda na década de 1960, abastece atualmente comerciantes multimarcas independentes e também suas franquias internacionais. As exportações, contudo, representam pouco no faturamento, cerca de $5 \%$.

As operações de produção na Ásia começaram em 2006, depois de anos de avaliação. O membro do Conselho de Administração entrevistado relatou não haver alternativa, para os fabricantes têxteis e vestuaristas que atuam como varejistas, senão produzir naquele continente: “À medida que uma C\&A ou uma Renner estão indo produzir na Ásia, você tem que seguir", disse, aludindo aos menores custos de produção na China.

Segundo o também entrevistado diretor administrativo, a operação na Ásia implica contratar a fabricação em plantas de terceiros (a empresa não possui fábricas naquela região) principalmente na China, em Bangladesh e na Índia. Trata-se, geralmente, de artigos acabados como jaquetas, bermudas, calças, camisas polo, shorts de banho, suéteres e itens de tricô. Em 2006, essa produção representou 3\% da produção total da Hering, um percentual que cresceu para 5\% em 2007 e para $12 \%$ em 2008 . Esses produtos, fabricados com marca própria da Hering, destinam-se tanto ao mercado nacional (lojas franqueadas e próprias) quanto ao exterior (lojas franqueadas na América Latina e no Oriente Médio, assim como as multimarcas nesses mercados). Quase 95\% se concentram no Brasil, todavia.

A Hering não aplica aos fabricantes asiáticos parâmetros de qualidade impostos por seus clientes. É a própria empresa que determina os procedimentos, em interações que incluem contratos trimestrais com os fornecedores. Nesse processo, utiliza-se equipe para controle de qualidade contratada na própria Ásia: além de ajudar na escolha dos fornecedores, sua atribuição inclui examinar os produtos antes do embarque para o Brasil. Mas uma equipe brasileira viaja a cada três meses para atualizar informações e contatar novos fornecedores.

Uma vez desembarcados, esses produtos vão para o Depósito Central da Hering em Blumenau, onde ocorrem operações de verificação da costura 
e solidez das peças e de etiquetagem. Depois, seguem para as lojas próprias e para as multimarcas atendidas pela empresa. Antes desse controle, os produtos já passaram pela mencionada inspeção na China, para evitar os custos provocados pela devolução.

Essa investida asiática ocorreu simultaneamente à busca, pela Hering, de reposição no mercado nacional, conforme a estratégia de aumentar a "acessibilidade" pela incorporação de produtos comercializáveis a preços menores. Na base estavam os resultados adversos do final dos anos 1990 e começo dos 2000, assim como a intenção de avançar como varejista. Informações do site da empresa são eloquentes a respeito:

A marca "Hering" tem um enorme potencial de crescimento, visto que a penetração na base de usuários potencial é baixa. (...) O maior limitante ao aumento de penetração (...), principalmente nas Classes B e C, é o fato de a marca ser associada por esses consumidores a produtos de preços mais elevados. Com o objetivo de capturar estes usuários, a companhia pretende reposicionar a marca 'Hering' como 'moda acessível', aumentando a oferta de produtos com preços mais acessíveis (...). (http://ciahering.investor-relations.com.br/2009)

A Hering produz em oito fábricas próprias, em Santa Catarina (cinco), Goiás (duas) e Rio Grande do Norte (uma). Além da produção contratada na Ásia, a empresa terceiriza em facções no Brasil: o propósito é "ampliar a terceirização, para responder ao aumento da demanda por seus produtos esperado para os próximos anos e, ao mesmo tempo, garantir alternativas de suprimento a custos menores" (A velha, 2009, s/p). Isso motivou a criação de departamento voltado ao desenvolvimento de fornecedores, dentro e fora do Brasil, contexto em que se insere a iniciativa de fazer produzir na Ásia.

O modus operandi da Hering na Ásia se assemelha ao de grandes varejistas mundiais. Os vínculos evocam as buyer driven chains, pois se trata de contratar fornecedores para produzir conforme parâmetros próprios, implicando coordenação nas interações estabelecidas. A própria Hering decide o que se produz e como isso ocorre, o que significa determinação do que será vendido pelos seus próprios clientes. Mas cabe o mesmo comentário sobre a Teka, relativamente aos detalhes dessas relações. O envolvimento apresenta aspectos de relational value chains e modular value chains, já que também os fornecedores detêm competências estratégicas: logram 
abastecer compradores em diferentes países, exibindo capacidade em tecnologia de processo e investimento. A "coordenação" protagonizada pela Hering, implicando definições produtivas e monitoramento dos processos, não significaria, assim, grande (se alguma) assimetria de poder.

\subsection{Buettner}

A Buettner tem somente uma fábrica (em Brusque, SC), e seus principais canais de vendas são o varejo multimarcas no Brasil e as lojas de departamentos no exterior, sem possuir lojas próprias. Voltada ao público de renda mais alta, a empresa reforçou parcerias com estilistas de moda almejando grafar assinaturas desses profissionais em suas coleções, uma iniciativa de associação entre moda e itens domésticos. A empresa também inovou em produto, com sofisticação traduzida, por exemplo, na incorporação de cristais Swarowsky em suas peças.

Tendo iniciado em 1972 as suas vendas no mercado externo, a Buettner vem demonstrando vigor nesse tipo de operação em certos períodos. Países europeus e os Estados Unidos constituem os mercados principais, e as exportações já chagaram a representar metade da produção, como em 2004. Mas essa participação caiu gradativamente, pelas dificuldades ligadas à valorização cambial, como assinalado em entrevista. Em 2008, as exportações representaram cerca de $15 \%$ do faturamento.

A empresa fizera poucas compras na Ásia até o momento da pesquisa, diferenciando-se, portanto, da Teka e da Hering. Contudo, seu presidente informou que importava da China e da Índia fios de algodão e corantes, além de peças para manutenção das máquinas. Tratava-se de fios totalmente de algodão ou com mistura, neste caso envolvendo, por exemplo, algodão e poliéster ou algodão e bambu. Essa importação, porém, era de ocasião, sem representar estratégia de estabelecimento de operações efetivas na Ásia. Quer dizer, a empresa importava quando enxergava vantagens na relação entre preços e câmbio e interrompia o negócio quando essa percepção desaparecia.

Segundo a pesquisa, não foi boa a experiência da Buettner na importação de itens prontos da Ásia. Talvez por isso se frisasse que, apesar das tentativas, não era possível dizer que a empresa recorria de fato à produção asiática, como na entrevista com o contador . 
A Buettner chegou a fazer compras na Ásia em 1996 como experiência. Trouxe edredons do Paquistão. Esse embarque chegou sujo e paramos de importar, e nunca mais retomamos, ainda que a empresa de vez em quando visite a Ásia para checar oportunidades. Existe a idéia (...) de adquirir insumos como fios diretamente, mas (...) não se conseguiu fornecedor a contento. Certa vez, [a empresa] comprou tais insumos como teste e também não recebeu na data estipulada. Hoje (...) a empresa importa ainda máquinas, como fazia em outros momentos, mas prefere não fazer produção fora.

$\mathrm{O}$ fato de operar com volumes pequenos dificultava as negociações com os asiáticos, tradicionais fabricantes de grande escala. Segundo o presidente:

Trazer produto acabado para a Buettner não dá certo porque é uma empresa que trabalha com nichos, com produtos diferenciados. Não tem grandes volumes. Em semiacabados, já chegamos a analisar [a possibilidade] na área de roupa de cama, mas até nisso poderá não ser interessante.

Entretanto, embora a empresa ainda não tivesse "se encontrado" na Ásia, como indicado, os interlocutores entendiam ser preciso vislumbrar formas de inserção nesse continente. Era coerente com isso uma nova pesquisa que a Buettner realizava desde 2008 na região, uma ação assim referida pelo presidente: “Ainda não está definido, mas provavelmente vamos trazer algum volume de semiacabados, principalmente do Paquistão e da China, para atender a demanda no mercado interno. Se não fizermos isso, ficamos fora do custo com o qual o mercado interno está trabalhando".

\section{UMA VISÃO DE CONJUNTO SOBRE DETERMINANTES E IMPLICAÇÕES DA "NOVA" INTERNACIONALIZAÇÃO}

Custos de produção mais baixos: eis um fator maior da investida asiática da Teka e da Hering nos termos apresentados. A Hering assinalou, além dos custos, a presença de "gargalos de produção" no Brasil, referindo às dificuldades para produzir domesticamente mercadorias que obtém na Ásia. Outros motivos foram a oportunidade para aprendizagem, os contatos com novos fornecedores e a obtenção de informações relevantes.

A atratividade se mantém mesmo com os aumentos de preço na China, resultantes, entre outras coisas, de uma intensa industrialização nos locais onde as empresas têxteis e vestuaristas dos outros países mais compram 
produção, pressionando os salários locais. "Mesmo assim, em determinados produtos, a China é imbatível, a Ásia é imbatível", no dizer do membro do Conselho de Administração da Hering, ilustrando o sentido de "imbatível" com menções a produtos mais baratos do que no Brasil em 30\%, 40\% e até $50 \%$. "E tem alguns [produtos] que nem se produz no Brasil por falta de expertise, por falta de matéria prima, e outros que ninguém se aventura a fazer pela situação cambial mais favorável às importações".

A Teka, frente aos crescentes custos na China, passou a cogitar a encomenda de produção em outros países também aptos a canalizar essas iniciativas. Vietnã, Camboja e Bangladesh apareciam bem cotados nesse sentido. O presidente da Buettner descreveu um cenário similar: “de 2007 para 2008 o preço do produto final na China já deve ter subido entre $10 \%$ e $15 \%$; mas ainda assim ela é muito competitiva em determinados tipos de produto".

As empresas também salientaram a importância do câmbio e dos impostos no Brasil. A experiência da Teka é sugestiva quanto ao câmbio. Tendo iniciado a produção asiática em 2006, recuou no início de 2008 devido à depreciação do real frente ao dólar na esteira da crise mundial. A entrevista foi eloqüente também sobre o papel dos impostos: "a primeira coisa mais importante na relação com a Ásia é o câmbio, e a segunda são os impostos de importação. Estes são de $26 \%$ a $35 \%$, muito altos se comparados com o mundo globalizado. Tem lugares [outros países] em que é zero". Mesmo assim a Ásia afigurava-se irresistível: "a gente não vai deixar de fazer negócio com os asiáticos. Vamos importar o quanto for necessário para a companhia”.

Outros vetores da investida asiática foram assinalados. Na Teka, além do preço, falou-se em qualidade e no caráter diferenciado dos produtos, comparativamente ao que a empresa realizava no Brasil. Disse o vice-presidente: "um exemplo é que um produto que usa 300 fios na sua composição, eu não fabrico no Brasil, e não tem quem faça isso hoje no país em grande volume e com qualidade e bom preço”. Já na Hering salientou-se a absoluta influência do câmbio, considerado "extremamente importante, sendo determinante para a continuidade do fornecimento" oriundo da Ásia.

Outro aspecto é que essa "nova" inserção na cadeia têxtil global forçou uma reorganização nas empresas. De um modo geral, houve ajustes na maneira de planejar e conduzir a fabricação, crescendo o tempo de programação das coleções. Também aumentaram as preocupações com logística e, pela 
incorporação de novos insumos, com design, beneficiário da expertise dos fornecedores asiáticos em fibras têxteis menos tradicionais. De outra parte, se as empresas passaram a recorrer à mão de obra de terceiros, também começaram a treinar equipes próprias para pesquisar e comprar produtos na Ásia, permanecendo na matriz, assim, uma das mais importantes etapas da cadeia produtiva: a da definição do produto.

Pistas sobre as implicações dessa "nova" realidade podem ser observadas na entrevista com o referido membro do Conselho de Administração da Hering.

Quando você compra da Ásia, tem que programar a sua coleção com muito mais antecedência, com 6 ou 7 meses. Antes, o ciclo de produção era mais curto porque eram fabricações locais, com respostas muito mais rápidas. Era de dois a três meses. Agora, dependendo do produto, você tem que encomendar bem antes. Estamos, por exemplo, no fim de maio de 2008 e estamos definindo o produto do inverno de 2009 , porque ele vai ter que ser comprado em julho ou agosto para poder embarcar em dezembro, para estar no Brasil no final de janeiro.

Assinale-se que não são poucas as dificuldades para fazer produzir no exterior. Problemas para encontrar os fornecedores certos e montar estruturas para controle de qualidade foram relatados. Na Hering enfatizou-se que é preciso tempo para conseguir o esquema adequado, tendo o interlocutor admitido tropeços no começo do vínculo na Ásia: "Compramos mal, compramos com problemas homéricos de qualidade, até acertar. $\mathrm{O}$ acerto ocorreu basicamente a partir de 2006". Uma outra entrevista na mesma empresa sublinhou a problemática da antecedência com que as compras devem ser feitas, na perspectiva da posterior venda, e também a questão do associado risco cambial, assim como o controle de qualidade, não obstante o desempenho da equipe montada na China para essa função.

Para o vice-presidente da Teka, as barreiras são diversas. Mas um aspecto específico foi destacado: "para produzir na Ásia (...) eu tenho que começar a pôr capital de giro no mínimo cinco ou seis meses antes. Essa é a parte mais difícil. Eu penso em Ásia um ano para a frente". O presidente da Buettner afirmou algo semelhante: "O problema é sempre a logística. A coleção precisa ser pensada seis meses antes. Mesmo no fio, tenho sinal de pedidos pago há 60 dias, e nem embarcado foi. No mínimo, um mês ou um 
mês e pouco de produto em casa você tem que ter, porque nunca se sabe quando embarcam".

Tudo somado, as três empresas sublinharam como principais determinantes na escolha de fornecedores internacionais: o preço baixo, a garantia de prazo e a facilidade de negociação. Em segundo plano, mas também importantes, apareceram o cumprimento de especificações técnicas, a garantia de qualidade e o conteúdo tecnológico dos insumos, além da inclinação para parcerias de longo prazo. Vincula-se ao último tópico a importância atribuída à troca de informações com esses fornecedores sobre produtos e matérias primas. É que as principais novidades surgem atualmente na Ásia, pois as empresas mundiais de ponta, em confecções e/ou em linhas para cama, mesa e banho, estão produzindo naquela região, mesmo que o design se origine nas matrizes, na Europa ou nos Estados Unidos.

\section{CONSIDERAÇÕES FINAIS}

As interações asiáticas das empresas estudadas são emblemáticas sobre as estratégias utilizadas em diferentes setores para enfrentar os desafios da globalização e aproveitar-lhe as oportunidades. A abordagem das cadeias mercantis globais "iluminou" essa estratégia. Em sintonia com esse debate, assinalou-se que tais interações evocam as buyer driven chains mencionadas anteriormente, um tipo de cadeia em que a governança é exercida por empresas compradoras que determinam e impõem os parâmetros de produção e "controlam" as operações de fornecedores localizados em diferentes países. Mas um ajuste no foco sugeriu situação em que se combinam atributos de relational value chains e até de modular value chains: embora acatem as especificações definidas por Hering e Buettner, os fornecedores possuem, eles próprios, competências estratégicas e, certamente, capacidade tecnológica e financeira, o que sugere simetria nas relações de poder.

Com efeito, as empresas pesquisadas mostraram interesse não só nos custos mais baixos que caracterizam a mão de obra asiática. Atribuíram importância também a fatores como qualidade da produção e o próprio fato de, no seu entendimento, a "revolução têxtil" estar passando por aquele continente, como evidenciado pela presença de escritórios de compra dos principais compradores mundiais principalmente na China. 
Essa investida teve consequências. As empresas precisaram rever o planejamento e a execução da produção, inclusive criando estruturas na China para controle de qualidade, e intensificaram o uso de insumos em cuja produção os asiáticos são muito competitivos, o que repercutiu em grande frequência de viagens à Ásia. Talvez o maior reflexo tenha sido a mudança no tempo de preparação e lançamento das coleções. A "incorporação" da produção asiática às suas estruturas de oferta exigiu que as empresas passassem a conceber a produção com antecedência de cerca de seis meses, impondo maior rapidez no trato com os lançamentos de coleções. $\mathrm{O}$ risco de erro também cresceu, talvez na mesma proporção.

Três aspectos merecem ênfase a título de considerações finais. Um é que essa projeção asiática ocorreu na esteira da atuação dessas empresas como fornecedoras, elas próprias, para grandes grupos internacionais, principalmente, até o início dos anos 2000. Assim, cabe falar em aprendizagem quanto à internacionalização, um processo que certamente influenciou a decisão de encomendar produção pronta ou semiacabada na Ásia. Isso se traduziu numa razoavelmente bem sucedida inserção em diversos países (China, Índia, Paquistão), onde compradores mundiais fazem produzir com marcas próprias e design próprio.

Outro aspecto é que as empresas estudadas protagonizaram na Ásia, utilizando capacidade de terceiros, "produção" complementar a das suas instalações catarinenses ou brasileiras, sem transferir atividades ou desativar linhas de fabricação próprias. Não surpreende, desse modo, não haver evidências de que essa investida tenha repercutido em desaparecimento líquido de postos de trabalho no Vale do Itajaí. A rigor, a Microrregião de Blumenau, centro têxtil e vestuarista do Vale do Itajaí, exibiu expansão do emprego formal em fabricação de produtos têxteis e em confecção de artigos do vestuário e acessórios entre 2000 e 2008 (Jurgenfeld, 2009). Tampouco houve reflexos negativos em termos salariais, a julgar pelas informações disponibilizadas no Sindicato dos Trabalhadores Têxteis de Blumenau, Gaspar e Indaial (SINTRAFITE, 2009).

Por último, não é injustificado cogitar que o prolongamento e aprofundamento do processo estudado neste artigo possam representar "transferência" efetiva de produção futuramente, com desativação de linhas de produtos. $\mathrm{O}$ câmbio afigura-se uma variável chave para um possível cenário 
desse tipo. Ora, o câmbio é um elemento estrutural, "sistêmico", sobre o qual nada se pode fazer em nível de localidade ou região. Esse aspecto evoca, entre outras coisas, os limites das intervenções no plano local e regional com vistas ao equacionamento de problemas causados por processos mais amplos. Evoca, numa palavra, a questão das margens de manobra para promover o desenvolvimento em escala territorial.

\title{
INITIATIVES OF TEXTILE AND GARMENT PRODUCERS OF SANTA CATARINA IN ASIA DURING THE 2000S: THREE CASES IN THE ITAJAÍ VALLEY
}

\begin{abstract}
In the 2000's some textile and garment producers of Santa Catarina began outsourcing finished and semi-finished products in Asia, mainly in China, to increase and diversify their offer in Brazil and abroad. The exchange rate was determinant for that initiative, which means governance through coordination and imposition of production parameters by buyers upon producers. This article analyses that strategy based on interviews in three companies of the Vale do Itajaí area (Santa Catarina state) - Hering, Teka e Buetner - and in local institutions. It is argued that the companies go to Asia because it means the principal world price reference in those industries today, due to low labor costs and high quality products. But the Asian production is just complementary to that of the companies and so does not mean interruption of local product lines. However, adjustments in planning production, mainly concerning the creation and presentation of collections, were necessary.
\end{abstract}

Key words: Global commodity chains; textile and garment production; Itajaí Valley; Asia

JEL Classification: L24, L27 


\section{REFERÊNCIAS}

ABIT (Associação Brasileira da Indústria Têxtil e de Confecção). Relatório sobre comércio exterior. URL [On line]: http://www.abit.org.br/site/ navegacao.asp?id_menu=9\&ID_Sub=29\&idioma $=$ PT\&id_ss_m $=6$ Acesso em: 15 de setembro de 2009.

ARRIGHI, Giovanni. A ilusão do desenvolvimento. 2. ed. Petrópolis: Vozes, 1997.

A VELHA dama no novo mercado. Época Negócios. URL [On line]: http://epocanegocios.globo.com/Revista/Common/0,EMI24079-16642,00$\mathrm{A}+\mathrm{VELHA}+\mathrm{DAMA}+\mathrm{NO}+\mathrm{NOVO}+\mathrm{MERCADO} . \mathrm{html}$. Acesso em: $8 \mathrm{de}$ janeiro de 2009, s/p.

BOVESPA. Relatórios de desempenho de Buettner, Teka e Hering. URL [On line]: www.bovespa.com.br. Acesso em: 18 de setembro de 2009.

BRAUDEL, Fernand. Civilização material, economia e capitalismo, séculos XV a XVIII. v. 3. O tempo do mundo. São Paulo: Martins Fontes, 1996.

FORNETTI, Verena. Importado invade coleção de grife nacional. Folha de S. Paulo, 4 abr., p. B9, 2010.

GEREFFI, Gary. The organization of buyer-driven global commodity chains: how U.S. retailers shape overseas production networks. In: GEREFFI, G.; KORZENIEWICZ, M. (eds.). Commodity chains and global capitalism. London: Greenwood Press, 1994, p. 95-122.

GEREFFI, Gary. Global production systems and third world development. In: STALLINGS, B. (ed.). Global Change, regional response: the new international context of development. Cambridge: Cambridge University Press, 1995, p. 100-142.

GEREFFI, Gary; KORZENIEWICZ, Miguel; KORZENIEWICZ, Roberto P. Introduction: global commodity chains. In GEREFFI, G.; KORZENIE- 
WICZ, M. (eds.). Commodity chains and global capitalism. London: Greenwood Press, 1994, p. 1-14.

GEREFFI, Gary; HUMPHREY, John; STURGEON, Timothy. The governance of global value chains. Review of International Political Economy, v. 12, n. 1, p. 78-104, 2005.

HENDERSON, Jeffrey; DICKEN, Peter; HESS, Martin; COE, Neil; YEUNG, Henry W-C. Global production networks and the analysis of economic development. Review of International Political Economy, v. 9, n. 3, p. 436-464, 2002.

JURGENFELD, Vanessa. Transformando ameaça em vantagem: novos acenos da indústria têxtil-vestuarista catarinense com a Ásia. Florianópolis: Monografia de Graduação, Universidade Federal de Santa Catarina, Curso de Ciências Econômicas, 2009.

KAPLINSKY, Raphael. Spreading the gains from globalization: what can be learned from value chain analysis?. IDS Working Paper, n. 110, Brighton: Institute of Development Studies, 2000.

SINTEX (Sindicato das Indústrias de Fiação, Tecelagem e do Vestuário de Blumenau). URL [On line]: www.sintex.org.br. Acesso em: 2 de maio de 2009.

SINTRAFITE (Sindicato dos Trabalhadores Têxteis de Blumenau, Gaspar e Indaial). URL [On line]: www.sintrafite.com.br. Acesso em: 2 de maio de 2009.

WALLERSTEIN, Immanuel. The essential Wallerstein. New York: The New York Press, 2000.

Artigo submetido para publicação em outubro de 2009 e aceito em maio de 2010. 